\title{
Q 20 \\ International Congresses on Transdisciplinarity: Their Importance for the Emergence of a Transdisciplinary Methodology
}

\author{
Basarab Nicolescu, CIRET, Paris (France) and University Babes-Bolyai, Cluj-Napoca, Romania, Email: \\ nicol@club-internet.fr
}

doi: $10.22545 / 2011 / 00021$

\begin{abstract}
$n$ this interview, Professor Basarab Nicolescu reveals important historical aspects on the emergence of an international community of transdisciplinary researchers, evaluates the role of different transdisciplinary meetings during the period 1986-2005, and analyzes the scientific and philosophical basis of the transdisciplinary methodology. ${ }^{1}$
\end{abstract}

Keywords: transdisciplinarity, Interview given by Basarab Nicolescu, logic of the included middle.

\section{Q-1 When did you begin to be interested in trans- disciplinary thought?}

- Since my adolescence, even though the word transdisciplinarity had not yet been invented. My first book, published in Romania in 1968, just a few months before my definitive departure for France-Ion Barbu, The Cosmology of the Second Game, Editura pentru Literatura, Bucharest, 1968 was devoted to the relations between mathematics and poetry in the work of a great

\footnotetext{
${ }^{1}$ Interview given by Basarab Nicolescu to Professor Augusta Thereza de Alvarenga of the Faculty of Public Health, University of São Paulo, Brazil (Translation from the French by Karen-Claire Voss).
}

Rumanian poet Ion Barbu, also known for being a mathematician of international reputation, named Dan Barbilian, who signed his poems using the pseudonym Ion Barbu.

\section{Q-2 How did you make this trajectory?}

- In a very natural way, I could even say "innate". As a student, I had solid knowledge in philosophy. My interest was concentrated on Schopenhauer and Hegel. Literature impassioned me, even if mathematics remained the center of my passions. Also, I had, very early, from the time I was around six years of age, a well-developed orthodox Christian education, with a priest who was one of the greatest Rumanian theologians - Father Galeriu. He gave me the taste for apophatic thought (particularly, Pseudo-Dionysus, Gregory of Nyssa, and Gregory Palamas), a taste which was developed by my practice of quantum physics and which was a fundamental component of the methodology of transdisciplinarity that I worked out after my arrival in France. Quantum physics was, for me, a place of conciliation between all its apparently con- 
tradictory concerns. My major references in the philosophy of quantum physics and mathematics were - and still are - Werner Heisenberg, Wolfgang Pauli, Niels Bohr and Kurt Gödel.

\section{Q-3 When and how did you propose a trans- disciplinary methodology based on three pillars: that of complexity, that of the various levels of reality, and that of the logic of the included middle?}

- I did not "propose" it: I worked it out. I formulated the methodology of transdisciplinarity in a series of articles published in the French review "3rd Millenium" (old series), which was included in my first book published in France We, the Particle and the World (Nous, la particule et le monde), Le Mail, Paris, 1985 (2nd edition: Rocher, Series "Transdisciplinarity", Monaco, 2002; translation in Portuguese:Nós, a particular e o universo, Colecção "Ciência e Conscência", Esquilo, Lisbon, 2005, translation in Portuguese by Isabel Debot).

\section{Q-4 How is this process carried out?}

- Very slowly. It seemed important to me to formulate a methodology, because in absence of this methodology, transdisciplinarity is only frivolous talk, a momentary fashion. But this methodology should be open, not dogmatic. This is why it seemed to me crucial that transdisciplinarity is defined via its methodology. A single methodology, which is the logos of method, is compatible with a great number of different methods. In other words, transdisciplinarity is based on a single methodology, but there can be variations of transdisciplinarity. This point is not generally understood even today; because even educated people confuse methodology and methods. My approach to thought is built on the example of the methodology of modern science: the one and only methodology, that formulated by Galileo, Newton and Kepler, that proved to be compatible with extremely different theories, like, for example, traditional mechanics (the two theories of relativity of Einstein included) and quantum mechanics. Another essential difficulty in the formula- tion of the methodology of transdisciplinarity is related to the irreducible presence of the Subject in transdisciplinarity. This is why it was clear for me that the methodology of modern science, founded on the exclusion of the Subject, is not valid in the field of the transdisciplinarity. The unification between hard (exact) sciences and soft (human) sciences cannot be accomplished using the methodology of modern science. A new methodology was necessary and, over the course of a few years, I have adhered to this formulation.

The first axiom (or "postulate" or "pillar", according to popular terminology), that concerning levels of Reality, seemed to me obvious, since 1970, from my own practice of quantum physics. But the idea did not exist in the extant scientific corpus and I hesitated to publish it. Fortunately, during my post-doctoral training course at Lawrence Berkeley Laboratory (1976-1977) I was in contact with Geoffrey Chew, the founder of the bootstrap theory, and also with Henry Stapp, who both encouraged me to publish it. I finally articulated the first axiom in an article published in "3rd Millenium", No 1, Paris, March-April 1982. Much later, in 1998, I learned that Werner Heisenberg had also proposed a formulation of the concept "level of Reality" (Werner Heisenberg,Philosophy - the Manuscript of 1942, Paris, Seuil, 1998. Translation from German and introduction by Catherine Chevalley. First German edition: Ordnung der Wirklichkeit, Munich, R. Piper GMBH $\S$ KG, 1989. Published first in W. Blum, H. P. Drr, and H. Rechenberg (ED.), W. Heisenberg, Gesammelte Werke, Vol. C-I: Physik und Erkenntnis, 1927-1955, Mnich, R. Piper GMBH $\S$ KG, 1984, pp. 218-306).

The third axiom, that concerning complexity was announced at the same time, in my book Nous, le particule et le monde. There are certainly a great many definitions of complexity, practically all incompatible with the concept of level of Reality. 
The only one which is appropriate for transdisciplinarity is that of Edgar Morin and Paul Cilliers.

Paradoxically it is the second axiom, that concerning the logic of the included middle, which was the most difficult to formulate. Of course, I had been working closely with Stéphane Lupasco since 1969. I knew also the considerations of Aristotle and, especially, Hegel, who applied this logic in his Philosophy of the Spirit. But it was obvious for me that a strictly formal logic was unsuited to transdisciplinarity, because it is very poor, and is limited to solving theoretical paradoxes. Moreover, the logic of the included middle of Lupasco did not take into account the existence of levels of Reality, but it had the capacity to be a true philosophy. This is why I extended and generalized the logic of Lupasco by introducing the levels of Reality of the Subject and the levels of Reality of the Object. The result was published, with the encouragement of Lupasco himself, in Nous, la particule et le monde. During the last few years, Joseph Brenner showed all the richness of such a logic in the study of the processes of Reality. Through this methodology, transdisciplinarity succeeds in becoming a tour de force that joins together ontology (the first axiom), logic (the second axiom), and epistemology (the third axiom).

I must affirm in all modesty (since I was the initiator or organizer of the majority of congresses) that I played a large role in the emergence of an international community of transdisciplinary researchers, brought together around an already extant methodology of transdisciplinarity. In this respect, one can certainly speak of a methodological consolidation. But it is not correct to speak of an "emergence" of methodology during these congresses, because this methodology existed already. It is true that I chose, for tactical considerations, to show this methodology gradually, the apogee being located at the 1st World Congress of Transdisciplinarity (1994) and the Congress of Locarno (1997). It should not be forgot- ten that the atmosphere in the academic milieu of the time was very unfavorable towards transdisciplinarity and it was necessary to proceed with courage but also with prudence.

Q-5 What do you think of the proposal that the three pillars considered in the official documents of the Congresses are of fundamental importance for the characterization of a methodology of transdisciplinarity? What are the possibilities and the challenges that this proposal brings, on the one hand, and, on the other hand, the limits that it presents?

- I have already answered the question concerning the importance of these congresses. One of the limits of transdisciplinary methodology is that it does not allow us to do science, on the technical level: the methodology of science is largely enough for that. In this respect, transdisciplinary methodology and scientific methodology are complementary. It may be nevertheless that transdisciplinary methodology leads to great scientific discoveries, especially in the study of consciousness.

The essential limit of transdisciplinary methodology is that it does not constitute a spiritual way in itself. It is here where potentially huge deviations of transdisciplinarity reside. I observe an occultist temptation here and there, which is extremely harmful and must be fought by transdisciplinary researchers. One should not forget that even if transdisciplinary methodology is very different from the methodology of science, it nevertheless has the scientific spirit in its center.

Q-6 Certain authors like Patrick Paul, of France, and Amâncio Friaça, of Brazil, argue the need for introducing a fourth pillar of transdisciplinarity to the three already allotted; i.e., the "paradox" (Formation of the Subject and Transdisciplinarity: History of Professional Life and the Imaginal. Paris: Harmattan, 2003, p. 401) and the "vacuum" ( $O$ vácuo e o espaço transdisciplinar in: Educação e transdisciplinaridade III. São Paulo: 
Triom, 2005, p. 439-451), respectively. Some others defend the need for noncentrality in the "logic of the included third" but in various nontraditional logics ("Message of Vila Velha/Vitòria", Brazil, of the Second World Congress of Transdisciplinarity). What do you think?

- It is not necessary to introduce a fourth axiom if it can be derived starting from the first three. The paradox and the vacuum are a consequence of the first three axioms. It is important to keep minimum axioms in the methodology of transdisciplinarity: if it leads to tautologies one obtains as a result of what one puts inside. Of course, the number three is neither magic nor sacred. If it is necessary, one can introduce a new axiom but, for the moment, it is not a necessity. I already answered the question of the "non-centrality" of the logic of the included middle. It is a question of confusion: the logic of transdisciplinarity, while including a formal logic is, at the same time, a philosophy, the philosophy of the included middle.

Q-7 Among the congresses on transdisciplinarity enumerated below, in which have you participated?

- Conference of Venice "Science and the Boundaries of Knowledge," Venice, in 1986

- Congress "Science and Tradition: Transdisciplinary Prospects for the 21st Century," Paris, in 1991

- First World Congress of Transdisciplinarity, Convento da Arrábida, Portugal, in 1994

- International Congress of Transdisciplinarity "Which University for Tomorrow?", Locarno, in 1997

- Second World Congress of Transdisciplinarity, Vitória, Brazil, in 2005.

I participated to all of them.

Q-8 Which is your perception of the importance of each congress in which you have participated for the emergence of transdisciplinary thought based on the three pillars?
- Conference of Venice "Science and the Boundaries of Knowledge": preparation of the emergence of a community.

- Congress "Science and Tradition: Transdisciplinary Prospects for the 21st century": preparation of the First World Congress.

- First World Congress of Transdisciplinarity: the core of the community is formed.

- International congress of Locarno: "Which University for Tomorrow?": participated of educators and students of the member states of UNESCO, in 1997.

- Second World Congress of Transdisciplinarity: With participation from the international community and a large number of transdisciplinary researchers in Brazil.

Q-9 We affirm, in one article, that one can think that such Congresses supported the constitution of what we could designate as a "community of transdisciplinary thinkers", (to employ the terminology of Thomas Kuhn) This is because we consider that many of those who took part in these congresses became followers and started to defend the idea that this proposal of a transdisciplinary methodology based on three pillars should be employed, in reflections on transdisciplinarity, like a basic diagram, or even like a paradigm (also in the design of $T$. Kuhn), because it is formed with the best methodological strategy available. What do you think of this assumption?

- I agree completely with this idea of a "community of transdisciplinary thinkers." But I have important reservations concerning the word "followers", with its connotation of the New Age. It is not necessary that transdisciplinarity gives rise to any kind of guru. I also have reservations concerning the word "paradigm", which was formulated by Thomas Kuhn in a precise context - that of science - and should not be used in other contexts.

Q-10 In your opinion, which is the strong point (or points) of this (these) same 
Congress(es) in which you have participated?

- Conference of Venice "Science and the Boundaries of Knowledge": the word "transdisciplinarity" is mentioned for the first time in an institutional document.

- Congress "Science and Tradition: transdisciplinary prospects for the 21st century": the entry into the transdisciplinary movement of the great Argentinean poet Roberto Juarroz, who in this context also formulated an important expression of the transdisciplinary terminology: "the transdisciplinary attitude".

- First World Congress of Transdisciplinarity: adoption of the Charter of Transdisciplinarity which is, today still, the most important document of the transdisciplinary movement.

- International congress of Locarno "Which University for Tomorrow?": formulation of the recommendations concerning the higher education addressed to the Member States of UNESCO.

- Second World Congress of Transdisciplinarity: demonstration of the vitality of the transdisciplinary movement in Brazil.

Q-11 And which are the weak point (or points) of this (these) same Congress(es), in your view?

- Conference of Venice "Science and the Boundaries of Knowledge": the conference was restricted to a small number of personalities of the cultural and scientific world.

- Congress "Science and Tradition: transdisciplinary prospects for the 21st century": mixed participation due to the double patronage by UNESCO and an association of engineers.

- First World Congress of Transdisciplinarity: no weak point. The organization this congress was ensured in an exceptional way by the great Portuguese painter Lima de Freitas and profited from the important intellectual contribution of the President of Portugal, Mario Soares.

- International congress of Locarno "Which University for tomorrow?": no weak point.
This congress profited from the participation of very important personalities, like the Nobel Prize Werner Arber and the great architect Mario Botta.

- Second World Congress of Transdisciplinarity: The document that came out of this congress was backward compared to the Charter of Transdisciplinarity. Moreover, it is too specific to the Brazilian movement and less adapted to the international community.

Q-12 In your opinion, what were the important challenges for the development and/or deepening of this proposal for transdisciplinarity, from the point of view of the methodological, epistemological and theoretical?

The challenges are unforeseeable. And the possible deviations are numerous.

Q-13 Can you identify some work or author (man or woman) (yourself including) already progressing, that it is from the theoretical point of view or the methodological /epistemological point of view, toward the point of embarking on transdisciplinarity? In the affirmative, could you mention the name of the work and its author (man or woman)? Could you tell us in what respect you consider that this author was making progress? ((Note: In case there are many authors (men or women) make a list of them, one by one, below).

I do not like the spirit of lists. To see which are the important personalities it is enough to observe which are the books or the articles most quoted in the transdisciplinary literature.

- See the translation of the Charter in nine languages, on the CIRET page http://basarab.nicolescu.perso.sfr.fr/ciret /indexen.html

Q-14 In many published articles, it is usual that the proposal of this transdisciplinary methodology, based on three pillars, is considered as a "paradigm". If one considers how the term "paradigm" was 
used in the traditional work by Thomas Kuhn ( Structure of Scientific Revolution), like a kind of "model" in which the problems of investigation are suggested by the paradigm and resolved by it, or, accepted as dominant by a given scientific community, whose function is to direct all research in a determined field, by furnishing problems and model solutions to a community of practicing scientists, what do you think about the nature and heuristic capacity of this proposal of "transdisciplinary methodology"? This proposal would be (or could be) in fact, a new paradigm, in the form of Thomas Kuhn, presenting itself as a hegemonic approach? Or should it be considered, considering the proper complexity of the topic, like one of the possible theoretic-methodologic propositions liable to be adopted by its followers and to contribute, with the extant or emerging others, to the study of transdisciplinarity? In the case of understanding it as a paradigm for the study of transdisciplinarity, what is your concept of paradigm?

I have already answered this question: in my view, one is not able to speak of a "paradigm" é propos of transdisciplinarity.

Q-15 By way of a final point, we would ask whether you consider it important to add still more comments, in the form of other questions which you consider important on the theme/subject and which we have not mentioned. If so, what would you add and why?

I thank you for these very intelligent questions.

\section{About the Author}

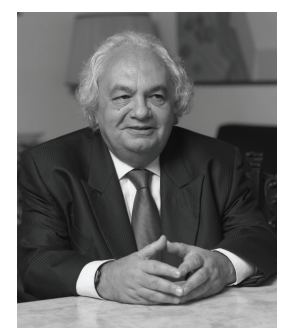

Basarab Nicolescu is a theoretical physicist in elementary particle physics at CNRS, France and professor of philosophy at the Babes-Bolyai University, Cluj-Napoca, Romania. He is member of the Romanian Academy and president-founder of the International Center for Transdisciplinary Research and Studies (CIRET). Basarab Nicolescu is founder and director of the Transdisciplinarity series, Rocher, Monaco, of the Romanians in Paris series, Oxus, Paris and of the Science and Religion and Science, Spirituality, Society Series, Curtea Veche, Bucharest. His books include: Manifesto of Transdisciplinarity, State University of New York (SUNY) Press, New York, 2002; Nous, la particule et le monde, E. M. E. InterCommunications, Brussels, 2012 (3rd edition); Science, Meaning and Evolution - The Cosmology of Jacob Boehme, Parabola Books, New York, 1991. He edited Transdisciplinarity Theory and Practice, Hampton Press, Cresskill, New Jersey, 2008. Forthcoming: Science, Culture and Spirituality From Modernity to Cosmodernity, State University of New York (SUNY) Press, New York (to be published).

Copyright (C) 2011 by the author. This is an open access article distributed under the Creative Commons Attribution License (https://creativecommons.org/licenses/by/4.0/), which permits unrestricted use, distribution, and reproduction in any medium, provided the original work is properly cited. 